\title{
Lifa Disease: Frictional Dermal Melanosis over Bony Prominences (Clinicopathological Study)*
}

\author{
Khalifa E. Sharquie ${ }^{1 \#}$, Muhsin A. Al-Dhalimi ${ }^{2}$, Adil A. Noaimi ${ }^{3}$, Hussein A. Al-Sultany ${ }^{4}$ \\ ${ }^{1}$ Scientific Council of Dermatology \& Venereology-Iraqi Board for Medical Specializations, Baghdad, Iraq; ${ }^{2}$ Department of Derma- \\ tology \& Venereology, College of Medicine, University of Kufa, Najef, Iraq; ${ }^{3}$ Department of Dermatology \& Venereology, College \\ of Medicine, University of Baghdad, Baghdad, Iraq; ${ }^{4}$ Department of Dermatology \& Venereology, College of Medicine University of \\ Babylon, Babylon, Iraq. \\ Email: "ksharquie@yahoo.co.uk
}

Received April 20 ${ }^{\text {th }}, 2012$; revised May 23 ${ }^{\text {rd }}, 2012$; accepted June $10^{\text {th }}, 2012$

\begin{abstract}
Background: Lifa disease (Frictional dermal melanosis over bony prominences) has been described in Iraq for the first time in 1993, as a new distinctive pigmentary skin condition that followed chronic friction with a body washing agent (lifa) during bathing. Objective: To assess this increasingly common problem where still many doctors unaware about its presence especially in other Middle East countries. Patients and Methods: A case series descriptive study done in Departments of Dermatology-Najaf and Baghdad Teaching Hospitals, between March 2007 - October 2008. Full history and clinical examination were done for all patients including Wood's light examination. Biopsies were taken from 21 patients and sent for hematoxylin-eosin and Congo red stains. Results: Fifty-two (49 females and 3 males) patients with typical clinical features of lifa disease were studied. The mean age of presentation was $27.92 \pm 7.58$ years. All patients were slim with prominent bones and low body mass index, used lifa vigorously during bathing. Pigmentation was distributed bilaterally and symmetrically over bony prominences. The most common affected sites were: clavicular areas (67.3\%) and upper back (42\%). Wood's light and histopathological examinations revealed dermal melanosis. No amyloid deposit was detected by using Congo red stain in any patient. Conclusions: Lifa disease is a common distinctive pigmentary disfiguring problem especially among females. The histopathology showed dermal melanosis, and might be confused with other pigmentary problems like macular amyloidosis.
\end{abstract}

Keywords: Frictional Dermal Melanosis; Lifa Disease; Macular Amyloidosis

\section{Introduction}

Pigmentary skin disorders are a major problem among Iraqi and other Asian countries as they had a bad cosmetic appearance and considered as a disfiguring diseases $[1$, 2].

Dermal melanosis is one of the important pigmentary problems, most commonly observed in inflammatory skin disorders, particularly in dermatoses that involve damage to the epidermal basal cells and/or to the dermoepidermal junction. Post-inflammatory dermal melanosis may occur following trauma (as friction and rubbing) or other inflammatory diseases as lichen planus [3].

Lifa disease (frictional dermal melanosis over bony prominences), seem to be a common problem especially in Iraq and other countries in the Asia and Middle East as Japan, Korea, India, Jordan [4-10]. The disease most

\footnotetext{
${ }^{*}$ This study was an independent study and not funded by any of the drug companies.

${ }^{\#}$ Corresponding author.
}

probably appears as a result of using rough washing agent like lifa in Iraq [4-6] and Jordon, scrub pad in Mexico [7], and nylon towel in Japan [8] and this problem could be easily mixed up with macular amyloidosis which is also prevalent in these countries [11-15]. In Iraq this problem was first reported in 1993 by Sharquie. The main features of this disease were the affection of slim females mainly, by pigmentation that occurs bilaterally and symmetrically over the bony prominences like clavicular areas, upper back, upper arms, and shins [4].

The aim of this study is to evaluate this common problem where still many dermatologists are unaware about its presence especially in other Middle East countries.

\section{Patients and Methods}

This case series, descriptive study was carried out in the Departments of Dermatology in Najaf, and Baghdad Teaching Hospitals, during March 2007 - October 2008. Fiftytwo patients were enrolled in this study. 
All patients had clinical features of lifa disease that characterized by rippled, spotty, or confluent macular hyper-pigmentation over the superficial bony prominences with bilateral and symmetrical distribution.

The patients were questioned regarding the: Age, sex, site of the lesions, age of onset and duration, presence of itching, presence of friction, duration and type of friction and agents used with special concern about usage of lifa (lifa in Iraq is made from fibers which is either of plant or plastic in origin (Figure 1)) during body bathing, history of administration of drugs, and history of topical application of medications or other chemicals. Also they were questioned about any associated skin or systemic diseases and family history of similar skin pigmentation in close relatives of the patients.

Careful physical examination was carried out to identify the site of the lesions, color, pattern of pigmentation, and distribution and symmetry of the lesions. Wood's lamp examination was performed for every patient and the enhancement of pigmentation was determined. The weight and the height of the patients were measured, and then body mass index (BMI) was calculated for all patients.

Laboratory studies including complete blood count $(\mathrm{CBC})$, renal and liver function tests were undertaken for each patient. Skin biopsies were taken from 21 patients, from the worst affected sites. Two staining methods were performed to each biopsy specimen, the ordinary hematoxylin-eosin and Congo red stains.

All patients were photographed by a digital camera in the same place with fixed illumination and distance by using a digital camera (Sony: Cyber shoot with resolution 7 mega pixels).

Ethical approval was performed by the scientific committee of the Scientific Council of Dermatology and Venereology-Iraqi Board for Medical Specializations, and informed consents were obtained from all participants in the study. We used the EPI INFO system version 3.5.1

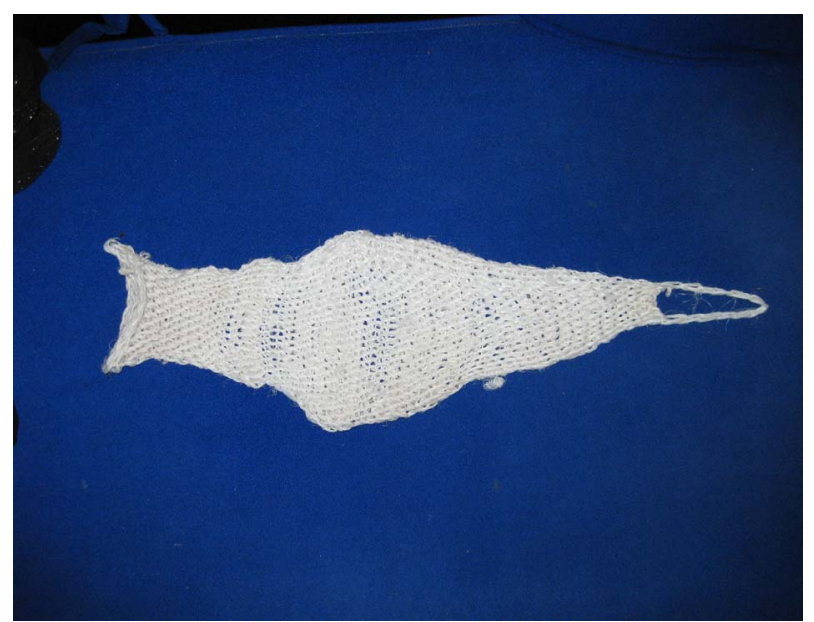

Figure 1. Lifa washing agent. for the statistical analysis of the results.

\section{Results}

Fifty-two patients were included in this study. Their ages at presentation ranged from $16-45$ years with a mean \pm SD of $27.92 \pm 7.58$ years. The disease duration varies between $0.5-12$ years with a mean \pm SD of $4.65 \pm 3.33$ years. The age of onset of the disease ranged from 15 38 years with a mean \pm SD of $23.19 \pm 6.31$ years. The disease started between 15 - 29 years in $43(82.6 \%)$ patients with a mean \pm SD of $20.95 \pm 4.24$ years. There were 49 (94\%) female patients and $3(6 \%)$ male patients with a female: male ratio of $16: 1$.

The main presenting feature in all patients was the bad cosmetic disfiguring pigmentation. Itching was found in $38(73 \%)$ patients.

All patients were slim with prominent bones and low BMI $<20 \mathrm{~kg} / \mathrm{m}^{2}$. The BMI of the patients ranged from $17.5-19.8 \mathrm{~kg} / \mathrm{m}^{2}$ with a mean \pm SD of $18.21 \pm 0.66,37$ $(71.2 \%)$ of the patients were underweight $(\mathrm{BMI}<18.5)$ and the remainder $15(28.8 \%)$ patients were within the lower normal level (18.5 - 19.9).

All patients gave history of using lifa vigorously during body bathing for long period before the appearance of the hyper-pigmentation.

No history of any associated skin and systemic diseases was given by any patient. There was no history of administration of drugs, or history of topical application of medication or other chemicals. Family history of similar skin pigmentation among close relatives of the patients was positive in $9(17.3 \%)$ patients.

The patients were presented with dark brown pigmentation, which was bilaterally and symmetrically distributed over the superficial bony prominences (Figure 2). The most commonly affected sites were: clavicular areas in $35(67.3 \%)$ patients, upper back $22(42 \%)$, lateral aspect of the arms $19(36.5 \%)$, shins $16(30.7 \%)$ and Adam's apple $14(26.9 \%)$ patients (Table 1).

The morphology and pattern of hyper-pigmentation were variable according to the site of involvement. The most common pattern was the rippled or reticulated form that was seen in $36(69.2 \%)$ patients especially on the clavicular areas, and neck (Figures 2 and 3). The hyperpigmented macules may coalesce to form large patches with small macules that could be seen at its periphery. This pattern of hyper-pigmentation was seen in 23 (44.2\%) patients especially on the upper back. Spotty (mottled) hyper-pigmented patches were seen in 19 (36.5\%) patients on the lateral aspect of the arms, shoulder and upper back. Different combinations of these patterns have been detected in many patients.

According to Fitzpatrick classification for skin types, $21(40.3 \%)$ patients were of skin type III, and $31(59.6 \%)$ 
Table 1. Predilection sites in lifa disease.

\begin{tabular}{|c|c|c|}
\hline \multirow{2}{*}{ Sites } & \multicolumn{2}{|c|}{ Patients } \\
\hline & No. & $\%$ \\
\hline 1-Chest: & 45 & $86.5 \%$ \\
\hline Clavicle & 35 & $67.3 \%$ \\
\hline Upper chest & 5 & $9.6 \%$ \\
\hline Sternum & 3 & $5.8 \%$ \\
\hline Ribs & 2 & $3.8 \%$ \\
\hline 2-Back: & 25 & $48 \%$ \\
\hline Upper back & 22 & $42 \%$ \\
\hline Whole back & 2 & $3.8 \%$ \\
\hline Midline of back & 1 & $1.9 \%$ \\
\hline 3-Upper limbs: & 24 & $46 \%$ \\
\hline Lateral aspect of arms & 19 & $36.5 \%$ \\
\hline Lateral aspect of forearms & 5 & $9.6 \%$ \\
\hline 4-Neck: & 22 & $42 \%$ \\
\hline Adam's apple & 14 & $26.9 \%$ \\
\hline Back of neck & 2 & $3.8 \%$ \\
\hline Sides of neck & 4 & $7.7 \%$ \\
\hline Whole neck & 2 & $3.8 \%$ \\
\hline 5-Lower limbs: & 10 & $7 \%$ \\
\hline Shins & 16 & $30.7 \%$ \\
\hline Thigh & 1 & $1.9 \%$ \\
\hline 6-Mandible: & 2 & $3.8 \%$ \\
\hline
\end{tabular}

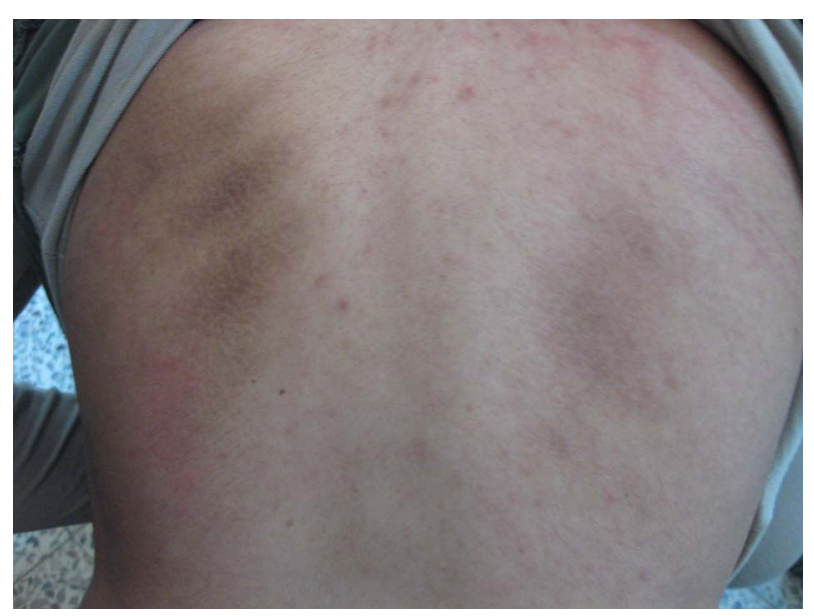

Figure 2. Bilateral and symmetrical distribution of rippled hyperpigmentation over the ribs.

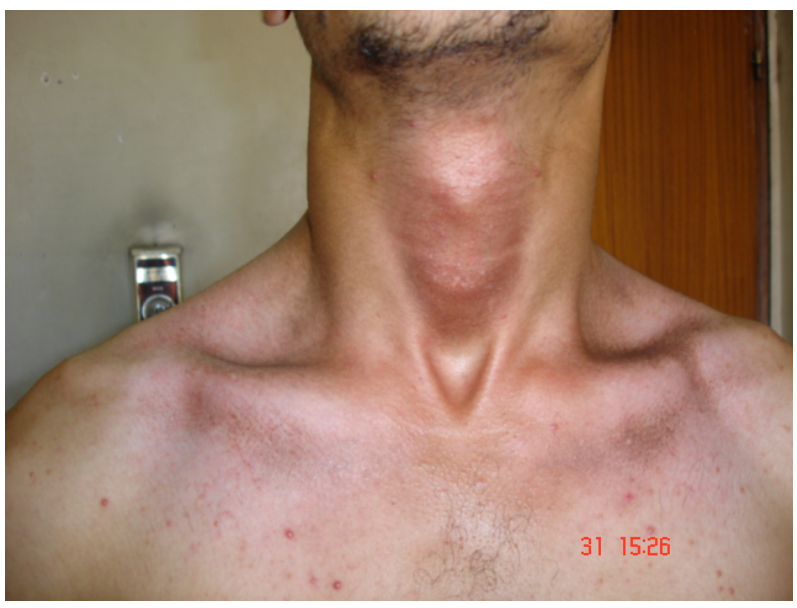

(a)

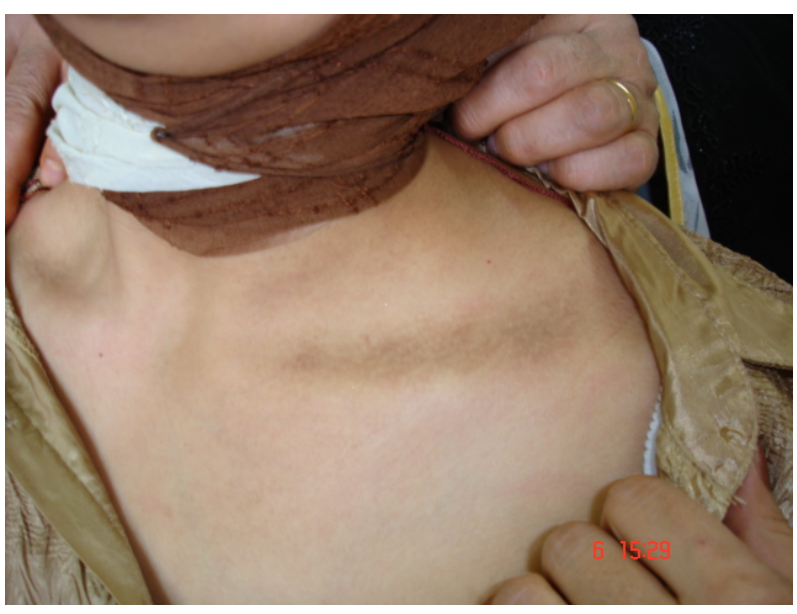

(b)

Figure 3. Bilateral and symmetrical distribution of rippled hyper-pigmentation over the clavicular areas.

patients were of skin type IV.

Wood's light examination in all patients showed no contrast enhancement, which indicated that this pigmentation is mainly dermal melanosis. The laboratory studies for all patients were normal.

The histopathology of biopsies from 21 patients showed:

1) Slight hyperkeratotic changes in a basket-weave configuration in $8(38 \%)$ patients (Figure 3);

2) The stratum granulosum was of normal thickness in all patients;

3) Acanthosis was detected in 3 (14\%) patients;

4) Diffuse continuous basilar hyper-pigmentation was seen in $16(76 \%)$ patients (Figure 3);

5) Striking degree of pigmentary incontinence with presence of melanin containing macrophages (melanophages) in the upper dermis was found in all patients (Figure 4);

6) Superficial perivascular lymphohistiocytic inflammatory infiltrate was seen in 7 (33\%) patients; 


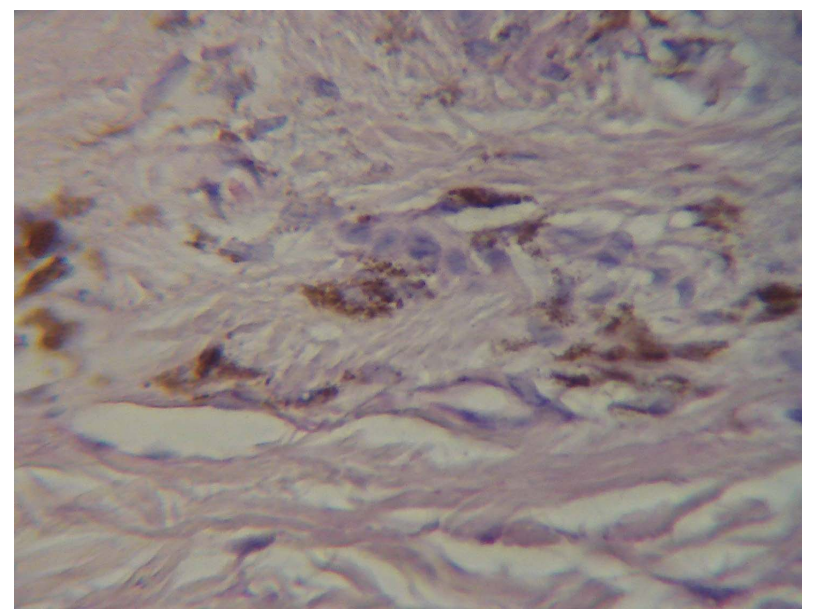

Figure 4. Pigmentary incontinence confined to the papillary dermis (HE, $\times 400)$.

7) No amyloid deposits were seen in any patient, with negative Congo red stain using polarized light in all cases.

\section{Discussion}

Lifa disease has been described in many countries including Iraq. It is often very disfiguring pigmentary disease especially among females [4-8].

The present study had shown that lifa disease was problem of young people with a mean age of onset of $23.19 \pm 6.31$ years. The disease duration varied between 0.5 - 12 years with a mean $\pm \mathrm{SD}$ of $4.65 \pm 3.33$ years. The patients gave history of using the lifa vigorously during bathing for long time before the appearance of the hyper-pigmentation. This gave a dirty appearance to the patient, followed by more vigorous rubbing friction which leads to aggravation and worsening of the condition.

Females were predominantly affected (94\%), with a female/male ratio of $16: 1$. These results were similar to the findings of previous studies [4-8]. This female predominance is probably because females take longer time during bathing and bath more frequently, and so more friction and more pigmentation. Also the musculature built of males probably prevents the squeezing and damage of the skin by the overlying washing agent.

This study showed that the pigmentation was dark brown and distributed bilaterally and symmetrically. The most common affected sites were the clavicular areas in $67.3 \%$, upper back in $42 \%$, lateral aspect of the arms in $36.5 \%$, shins in $30.7 \%$ and Adam's apple in $26.9 \%$ of cases. The most common pattern of pigmentation was the rippled pattern especially over the clavicular areas followed by confluent macular and spotty (mottled) pattern. These findings were similar to that from previously published studies [4,5].
The pigmentation was dermal as revealed by wood light and histopathological examination, and this is similarly reported [4-8].

The disease affects mainly slim people with low BMI. The disease is often chronic, but could be self limited if the patient stops the use of lifa for long time [10] and especially if the patient becomes obese. It is obvious that obesity is a protective factor against the development of lifa disease, as the fat in the subcutaneous tissue works as a cushion like and prevents the damage of the basal cell layer by lifa. When the patient is slim the epidermis especially basal layer would be squeezed between the washing agent and the underling bone as a part of mechanobiology of the melanocytes which lead to pigmentary incontinence [4].

Histopathology of the disease had been studied but the cases were few in other reports $[4,6,7]$. The present work included a histopathological examination in 21 patients using hematoxylin and eosin stain and Congo red stain. The main finding was mainly dermal melanosis in the form of melanophages in the papillary dermis; while amyloid deposition was not seen in any case and this is different from Sharquie's study that found amyloid deposits in $10 \%$ [4]. This raises a problem how we can differentiate between lifa disease and macular amyloidosis that has many common sharing features including:

1) Macular amyloidosis is a common condition among Asian and Middle East people, including Iraqis especially females [11-15];

2) The features of pigmentation are similar in both macular amyloidosis and Lifa disease. Sometimes we may have a combination of both of them in the same patient $[14,15]$;

3) The histopathology of both conditions consists of dermal melanosis $[14,15]$;

4) Amyloid deposition could be seen in both diseases but more commonly in macular amyloidosis. Even in the latter, the amyloid deposition might be so small that examination of repeated biopsies and multiple sections is necessary for its detection [14].

In conclusion, lifa disease is a common pigmentary disfiguring problem especially among young slim females, where the histopathology is mainly dermal melanosis. It could be mixed up with other pigmentary diseases.

\section{REFERENCES}

[1] M. Kurita, H. Kato and K. Yoshimura, "A Therapeutic Strategy Based on Histological Assessment of Hyperpigmented Skin Lesions in Asians," Journal of Plastic, Reconstructive \& Aesthetic Surgery, Vol. 62, No. 7, 2009, pp. 955-963.

[2] T. B. Fitzpatrick and J. P. Ortonne, "Normal Skin Color and General Considerations of Pigmentary Disorders," In: I. M. Freedberg, A. Z. Eisen, K. Wolf, K. F. Austin, L. A. 
Goldsmith and S. Katz, Eds., Fitzpatrick's Dermatology in General Medicine, 6th Edition, McGrow-Hill, New York, 2003, pp. 819-825.

[3] J. P. Ortonne and J. J. Nordlund, "Mechanisms That Cause Abnormal Skin Color," In: J. J. Nordlund, R. E. Boissy, V. J. Hearing, R. A. King, W. S. Oetting and J. P. Ortonne, Eds., The Pigmentary System: Physiology and Pathophysiology, 2nd Edition, Blackwell Scientific Publication, New York, 2006, pp. 521-535.

[4] K. E. Sharquie, "Frictional Dermal Melanosis (Lifa Disease) over Bony Prominences," Journal of the Faculty of Medicine, Baghdad, Vol. 35, 1993, pp. 83-87.

[5] K. E. Sharquie and M. K. Al-Dorky, "Frictional Dermal Melanosis (Lifa Disease) over Bony Prominences," The Journal of Dermatology, Vol. 28, No. 1, 2001, pp. 12-15.

[6] M. Al-Aboosi, A. Abalkhail, O. Kasim, A. Al-Khatib, F. Qarqaz, D. Todd, et al., "Frictional Melanosis: A Clinical, Histologic, and Ultrastructural Study in Jordanian Patients," International Journal of Dermatology, Vol. 43, No. 4, 2004, pp. 261-264. doi:10.1111/j.1365-4632.2004.01606.x

[7] M. MaGana-Garcia, G. Carrasco, R. Herreva-Goepfert and S. Pueblitz-Peredo, "Hyperpigmentation of the Clavicular Zone: A Variant of Friction Melanosis," International Journal of Dermatology, Vol. 28, No. 2, 1989, pp. 119122.

[8] A. Hidano, M. Mizuguchi and Y. Higaki, "Friction Melanosis," Ann Dermatol Venereol, Vol. 111, No. 12, 1984, pp. 1063-1071.

[9] H. E. Kang, S. H. Rhee, Y. C. Kim and E. S. Lee, "Fric- tion Melanosis and Striae Distensa Caused by Stretch Training on a Bench Press," The Journal of Dermatology, Vol. 32, No. 9, 2005, pp. 765-766.

[10] V. G. Probhakara, S. Chandra and D. S. Krupa, "Frictional Pigmentary Dermatoses: A Clinical and Histopathological Study of 27 Cases," Indian Journal of Dermatology, Venereology and Leprology, Vol. 63, No. 2, 1997, pp. 99-100.

[11] S. M. Hasson, "Primary Cutaneous Amyloidosis in Iraqi Patients: Epidemiological, Clinical and Histopathological Study," Diploma Dissertation, University of Baghdad, Baghdad, 1991.

[12] T. Tan, "Epidemiology of Primary Cutaneous Amyloidosis in Southeast Asia," Clinics in Dermatology, Vol. 8, No. 2, 1990, pp. 20-24.

[13] R. P. Sarkany, S. M. Breathnach, C. A. Setmour, K. Weismann and D. A. Burns, "Metabolic and nutritional Disorders," In: T. Burns, S. Breathnach, N. Cox and C. Griffiths, Eds., Rook's Text Book of Dermatology, 7th Edition, Blackwell Scientific Publication, Blackwell Scientific, Italy, 2004, pp. 57.36- 57.50.

[14] M. M. Black and E. W. Jones, "Macular Amyloidosis: A Study of 21 Cases with Special Reference to the Role of the Epidermis in Its Histogenesis," British Journal of Dermatology, Vol. 84, No. 3, 1971, pp. 199-209. doi:10.1111/j.1365-2133.1971.tb14208.x

[15] C. K. Wong and C. S. Lin, "Friction Amyloidosis," International Journal of Dermatology, Vol. 27, No. 5, 1988, pp. 302-307. doi:10.1111/j.1365-4362.1988.tb02357.x 